\title{
SNPs Cumulating to Genetic Variation for Fertility in Crossbred (Bos taurus $X$ Bos indicus) Bull Spermatozoa
}

Manish Kumar Sinha ( $\sim$ manishkumarsinha002@gmail.com )

Jain University

\section{Arumugam Kumaresan}

National Dairy Research Institute Southern Regional Station Bangalore https://orcid.org/0000-00028061-3477

\section{Thirumala Rao Talluri}

NRCE: National Research Centre on Equines

\section{John Peter Ebenezer Samuel King}

Jain University

\section{Mani Arul Prakash}

Tamil Nadu Veterinary and Animal Sciences University

\section{Pradeep Nag}

National Dairy Research Institute Southern Regional Station Bangalore

Nilendu Paul

National Dairy Research Institute Southern Regional Station Bangalore

Kathan Raval

National Dairy Research Institute Southern Regional Station Bangalore

Elango Kamaraj

National Dairy Research Institute Southern Regional Station Bangalore

Aranganathan V

Jain University https://orcid.org/0000-0002-5586-0636

\section{Research Article}

Keywords: SNP, Next-generation Sequencing, Bull fertility, Novel variant

Posted Date: February 2nd, 2022

DOI: https://doi.org/10.21203/rs.3.rs-1295629/v1

License: (c) (i) This work is licensed under a Creative Commons Attribution 4.0 International License.

Read Full License 
Version of Record: A version of this preprint was published at Animal Biotechnology on September 22nd, 2022. See the published version at https://doi.org/10.1080/10495398.2022.2124166. 


\section{Abstract}

Purpose: The objective of the present study is to identify important polymorphisms at single nucleotide in Holstein crossbred bull spermatozoa and to identify genetic variants significantly influence or associated to bull fertility.

Methods: Spermatozoa from high- (HF) and low-fertile (LF) breeding bulls were subjected to high throughput Next-generation sequencing to identify important SNPs and novel variants associated with fertility.

Results: A total of 77,036 genome wide SNPs were identified in the crossbred bull spermatozoa with a minimum read depth of 20 , and among them, 10,269 were observed to be novel variants. A total of 42,290 and 34,748 variants were recorded in HF and LF bulls respectively, among which 6115 and 4673 were found to novel in respective group. Higher number of SNPs and Indels were identified in HF compared to LF bulls. GO analysis of filtered genes with significant variation in HF bulls indicated their enrichment in various important pathways like oxidative phosphorylation and metabolic pathways. On the other hand, GO analysis of filtered genes with significant variation in LF bulls revealed their involvement in $\mathrm{Ca}^{2++}$ ion binding, structural constituent of ribosome, and biological processes like translation and ribosomal small subunit assembly.

Conclusions: The study identified SNPs in candidate genes including TPT1, BOLA-DRA, CD74, RPS17, RPS28, RPS29, RPL14, RPL13 and RPS27A, which are linked to sperm functionality, survival, protection from oxidative stress and bull fertility. The identified SNPs could be used as a tool for identification and selection of bulls for high fertility upon validation in large number of bulls

\section{Introduction}

The decline in the reproductive efficiency of dairy cattle has become a challenging problem worldwide, and it may cause colossal loss to the dairy industry (Lucy 2001; Pryce et al. 2004). Although both dam and sire contribute to reproductive success, much of the research on dairy cattle has been directed towards cow fertility. In contrast, bull fertility has received much less consideration, and the potential contributions of the bull have been largely ignored. Recent research envisages that a significant percentage of reproductive failure in dairy cattle is attributed to infertility or subfertility in bulls (DeJarnette et al. 2004). This emphasises the fact that bull fertility cannot be disregarded in breeding schemes aimed at improving the reproductive performance of dairy cattle (Braundmeier and Miller 2001). Bull fertility is important because a single bull is being used to produce the several thousands of semen doses that are further used for inseminating large number of cows. Thus the economic impacts of bull fertility greatly influence the Al industry (Ostermeier et al. 2002). A recent review emphasised the need for developing markers for bull fertility, especially in case of crossbred bulls. Crossbreeding of indigenous cattle (Bos indicus) with improved (Bos taurus) breeds gained momentum and economic relevance in several countries to increase milk production. While production performance of the crossbred offspring is 
high due to hybrid vigour, they suffer from a high incidence of reproductive problems, especially the infertility problems in crossbred males as compared to purebred bulls (Kumaresan et al. 2021).

Currently, Bulls are evaluated based on a breeding soundness exam (BSE) that is composed of preliminary inspection of basic semen quality attributes such as sperm morphology, sperm concentration and sperm motility (DeJarnette et al. 2004) combined with a phenotypic evaluation of bulls' features. Despite great efforts to evaluate bulls using BSE, bull fertility is deemed suboptimal under field conditions, with a conception rate varying from 20 to $40 \%$ (Kumaresan et al. 2021). Such differences may be due to subtle sperm subpopulations and sperm abnormalities that might be overlooked using current, established techniques. Indeed, there is growing evidence that the reduced ability of low-fertility bulls to establish pregnancy is multifactorial, including sperm fertilising ability, preimplantation embryonic development, and placenta and embryo development (DeJarnette et al. 2004; Kropp et al. 2014; Immler 2018; Ortega et al. 2018). The source or aetiology for the potential differences in bull fertility may be genetic or epigenetic (Taylor et al. 2018). A growing body of science suggests that genetic factors explain part of this difference in fertility among the sires and evaluation of service sire/bull needs much attention (Butler et al. 2020). Genetic variants with moderate to significant effects on fertility can be identified by sequencing the genomes of high -and low fertile (HF and LF) and sub-fertile or infertile sires (Taylor et al. 2018).

In the recent past, there has been much acceleration in the application of high-throughput sequencing technologies for the rapid screening of thousands of molecules about bull fertility. Employing these emerging techniques, several studies identified the molecular differences between the spermatozoa of high- and low-fertility bulls (Peddinti et al. 2008; Feugang et al. 2010; Aslam et al. 2018; DasGupta et al. 2021; Paul et al. 2021; Prakash et al. 2021). Identifying genomic regions, and preferably individual genes responsible for genetic variation in bull fertility will enhance the understanding of biological pathways involving this trait and may point to opportunities for improving sire fertility via selective breeding. Genetic estimates of fertility can be improved by studying genome-wide associations and by employing single nucleotide polymorphism (SNP) arrays. SNPs represent the most abundant genomic variation, have proved helpful in studies of genes associated with human diseases like cancer, stroke, and diabetes (Craig and Stephan 2005; Newton-Cheh and Hirschhorn 2005; Suh et al. 2005; Tishkoff et al. 2007) and important economic traits in livestock (horse, pig, and cattle) (Heaton et al. 2002; Haegeman et al. 2003; Werner et al. 2004; Vallet et al. 2005; VychodilovaKrenkova et al. 2005). Many bulls are now genotyped for thousands of SNP markers used in genomic evaluation of breeding value (Hayes et al. 2009).

Bovine whole genome sequence information (Zimin et al. 2009), combined with estimated effects of many SNP can readily facilitate localisation of specific genes or gene regions related to traits of interest. Many GWAS using the bovine $50 \mathrm{~K}$ SNP chip has been reported, but mostly for milk production, conformation, and health traits routinely evaluated in dairy cattle breeding programs (Mai et al. 2010; Cole et al. 2011; Meredith et al. 2013). Such studies provide an excellent opportunity to perform CaseControl studies aimed at identifying candidate genes for fertility in bulls. According to an estimate, currently over and about 3000 cattle genomes have been sequenced worldwide revealing more than 100 
million polymorphisms. dbSNP build 151 contains over 104 million entries for Bos taurus and over 17 million entries for Bos indicus. Many of these variants create variation in male fertility, however, the specific polymorphisms that affect sperm phenotypes and fertilising ability, or that cause early embryo loss, are largely unknown. Detection of candidate genes may provide valuable information for better understanding of genetic determinism of phenotypes and for identifying causal polymorphisms that can lead to more efficient genetic improvement using SNP-assisted selection. The previous use of SNPs for fertility studies has been limited to a few markers, and their implication in male infertility has not yet been fully elucidated. Hence in the current study we aimed at identifying the various genetic variants significantly related to fertility by through screening of the SNPs in the transcripts related to with highand low fertile bulls.

\section{Materials And Methods}

\section{Ethical approval statement}

The current study was carried out at the Theriogenology Laboratory, Southern Regional Station of ICARNational Dairy Research Institute, Bengaluru, India. All the experiments and procedures adopted in this study were approved by Institute Animal Ethical Committee (CPCSEA/IAEC/LA/SRS-ICAR-NDRI2019/No.04).

\section{Experimental animals and samples}

The experimental bulls (Holstein Friesian crossbred; $n=12$ ) were selected based on their high genetic merit and BSE and were routinely used for an artificial breeding programme. Based on their field conception rates $(C R)$, the bulls were classified into high- and low - fertile ( $n=6$ each) based on their field CR. CR for each bull was calculated based on the proportion of pregnant animals to the total number of inseminations per bull (up to 3rd insemination). Further, CR was adjusted to non-genetic parameters according to the procedure described previously by (Singh et al. 2016). Bulls with CR Mean +1 standard deviation were considered as high fertile and Mean - 1 standard deviation was considered as low fertile. Cryopreserved spermatozoa from the experimental bulls (6 high- and 6 low-fertile) were used for RNA-Seq analysis.

\section{Extraction of RNA and cDNA synthesis}

For RNA extraction, semen was purified using Percoll gradient ( $90-45 \%$ discontinuous) centrifugation to eliminate the semen extender and epithelial cell contamination. Total RNA was extracted from frozen sperm using TRIzol (Ambion, Thermo Fisher Scientific, United States) (Prakash et al. 2021) with minor modifications. Quantification of RNA was done by NanoDrop (ND-1000, Thermo Fisher Scientific, United States). RNA samples with good quality (260/280 ratio of $1.85-2.0)$ were selected for cDNA synthesis (reverse transcription). cDNA synthesis was done using a combination of oligo (dT) and random hexamers with an initial concentration of 50-100 ng of total RNA from each crossbred bull spermatozoa sample using the RevertAid First Strand cDNA Synthesis Kit (Thermo Fisher Scientific, United States, 
Catalog number K1622) based on the manufacturer's instructions of $20 \mu \mathrm{l}$ final volume. The cDNA samples were stored at $-20^{\circ} \mathrm{C}$ until further processing. Two representative CDNA samples were made from the six high-fertile bulls by pooling equal quantities of sperm cDNA from three high-fertile bulls each. Similarly, two representative cDNA samples were prepared from three low-fertile bulls. All the samples (two pooled samples from each group) were subjected to Illumina Nextseq-500 sequencing system for analysis.

\section{Library construction and sequencing}

The transcriptome library was produced with the NEB Ultra II RNA library prepkit (Illumina, United States) and sequenced with Illumina NextSeq 500 paired-end technology (Illumina, United States). The NEB Magnetic mRNA Isolation Kit was used to enrich mRNA from total RNA (1 g) (Illumina, United States). Fragmentation buffer was used to fragment the enriched mRNA (about $200 \mathrm{bp}$ ). Random hexamer primers were then added and hybridised to complementary RNA sequences. The first strand of cDNA was synthesised by using fragments as templates and done by using reverse transcriptase and dNTP. The DNA-RNA hybrids produced during first strand cDNA synthesis are converted into full-length doublestranded cDNAs using RNase $\mathrm{H}$ and Escherichia coli DNA polymerase I. Second strand enzyme mix and buffer were used for obtaining the second strand of cDNA. 1.8AMPure beads were used for purifying the double-stranded cDNA fragments. The adaptor-ligated DNA was subsequently purified using AMPure beads and enriched with particular primers that were compatible with Illumina platforms for sequencing. A Qubit ${ }^{\circledR}$ Fluorometer was used to quantify the final enriched library, and a bio-analyser was used to determine its size.

\section{Data analysis}

Total RNA-seq analysis was performed against the Bos taurus reference genome and quantified the number of mutational events using bcftool. Identified variants were annotated using the VEP (Ensembl Variant Effect Predictor) program. The sequence data quality was assessed using the FastQC version 0.10.0 (Andrew 2010). The raw data generated in fastq format was formatted by trimming, removing the adapters and length filtering (minimum of $15 \mathrm{bp}$ reads are retained). Further, the data were aligned against the Bovine genome using "HISAT2" program that maps the processed data to the reference genome resulting .bam files.

\section{Variant calling, annotation, and analysis}

The aligned samples and the reference genome sequence were used for variant (SNP and indels) calling. We further processed the .bam files for the identification and acquisition of variants by employing multiple bioinformatic tools like "Samtools" / "bcftool" (Li et al. 2009) for variant calling and "mpileup" programme "mpileup" function was used for generating a pileup file that provides a single-base resolution of coverage, i.e., coverage of mapped reads to the reference. Significant variants with a minimum quality of Phred score Q30 and minimum coverage at each base depth of 20 were obtained using the "varFilter" function and filtering the $v c f$ file. The identified variants were filtered using the 
VCFtools version 0.1.8 (Danecek et al. 2011). The SNPs discovered were annotated both structurally and functionally with the help of SnPEFF (Cingolani 2010). This annotation is carried against the database reference bovine genome and $g f f$ (general feature file). The SNPs obtained after the variant calling were compared with the cattle SNPs in dbSNP (build 150) of NCBI to identify the novel SNPs. The variants identified in the study were mapped to genomic regions harbouring the major candidate genes identified through association studies for production traits in dairy cattle (Nayeri and Stothard 2016).

\section{Gene Ontology analysis and Functional annotation}

Gene ontology analysis for the critical genes with differential expression of SNPs related to fertility and for the novel variants and KEGG pathway analysis was carried for important genes involved in biological and molecular processes. Interaction network analysis of combined GO categories and pathway analysis among the SNPs was performed using ClueGo (Version 2.5.4, Integrative Cancer Immunology, Jerome Galon) and Cluepedia (Version 1.5.4) plugins in the open source Cytoscape (Version 3.7.1, National Institute of General Medical Sciences (NIGMS), USA) platform (Locatelli et al. 2019) and obtained as different layouts.

\section{Results}

\section{Total variants in crossbred bull spermatozoa}

With Illumina, Next Seq-500 RNA sequencing, the total raw data of about 115 million reads were generated. Further, raw data processing resulted in 97 million reads, which were mapped against the Bos taurus genome (ARS-UCD1.2 - GCA_002263795.2). A total of 77,036 genome wide SNPs identified in the crossbred bull spermatozoa with reference to the Bos indicus genome (Bos_indicus_1.0) with a minimum read depth of 20 , and among them, 10,269 were observed to be novel variants. All these variants were found to have a minimum quality of $q 30$ and coverage of 20 . A total of 42,290 and 34,748 variants were recorded in high- (HF) and low-fertile (LF) bulls, respectively, among which 6115 and 4673 were found to be novel in HF and LF groups of bulls respectively. The venn diagram showing the total and novel variants were represented in Fig $1 \mathrm{~A}$ and $1 \mathrm{~B}$ respectively. The total variants identified in each sample were annotated using the VEP database (Ensemble Variant Effect Predictor database). The details of total variants, existing and novel variants observed in HF and LF group bulls were presented in Table 1. A Circos plot was also generated for the global distribution of SNP variants, novel variants and signature of selective sweeps along the 29 autosomes and X (Fig 2 A and 2B). The genes with variants and genes with novel variants were also identified and presented in a venn diagram in Fig 3A and 3B.

The coding region consequences were enumerated in the HF and LF bulls and are classified as synonymous variants, missense variants, frameshift variants, stop retained, stop loss and stop gained. The data for the same is presented in Fig. 4A and 4B. In the identified SNPs, silent mutations were most frequent among the functional class, followed by missense mutations and non-sense mutations (Table 2). Classifying SNPs based on the genomic region, maximum SNPs were found in intron specific regions followed by intergenic regions (Supplementary Fig. 1). The missense to silent ratio was also presented in 
Table 3.The Ts/Tv ratio was found to be 1.89, comprising of 52340 transitions and 25613 transversions (Table 3). The number of G/C and T/G substitutions was relatively lower than other types of substitutions (Table 4).

\section{Gene Ontology (GO) analysis}

GO analysis was carried for the specific genes with novel mutations (1127) in HF groups and specific genes with novel mutations (783) genes in LF group. For the HF group, genes with novel spermassociated variants revealed their involvement in 27 molecular functions (MFs), 79 biological processes (BPs), and 32 cellular components (CCs (the top 10 in each GO category are shown in Figure 5, (Supplementary Table 1) and 59 KEGG pathways (Supplementary Table 2). Similarly, LF group genes with novel sperm associated variants revealed their involvement in $21 \mathrm{MFs}, 37 \mathrm{BPs}$, and 7 CCs (the top 10 in each GO category are shown in Figure 5, (Supplementary Table 3) and 12 KEGG pathways (Supplementary Table 4).

GO analysis of filtered genes with significant variation (92) in the spermatozoa of HF bulls revealed their involvement in $7 \mathrm{MFs}, 3 \mathrm{BPs}$, and $12 \mathrm{CCs}$, and $3 \mathrm{KEGG}$ pathways. The genes listed were involved in various important molecular functions like $\mathrm{Zn}$ and $\mathrm{Mg}$ binding, phospholipid-translocating ATPase activity and biological processes like ATP synthesis coupled proton transport and complement activation, classical pathway. The filtered genes were also found to be enriched in various important pathways like oxidative phosphorylation and metabolic pathways. GO analysis of filtered genes with significant variation (64) in the spermatozoa of HF bulls revealed their involvement in 4 MFs, 3 BPs, 8 CCs categories, and 2 KEGG pathways. The genes listed involved various important molecular functions like $\mathrm{Ca}^{2++}$ ion binding, structural constituent of the ribosome and biological process like translation, ribosomal small subunit assembly.

\section{Network and Pathway analysis}

Pathway enrichment of genes in the HF group with novel sperm variants revealed that they were enriched in important pathways like cAMP signalling pathway ( 26 gene counts), Calcium signalling pathway ( 24 gene counts), and top ten enriched pathways are shown in Figure 6 A. In the LF group, the pathway analysis of genes with novel variants enriched in their involvement in the ribosome (47 gene counts), regulation of actin cytoskeleton (18 gene counts), Endocytosis (16 gene counts), and Ubiquitin mediated proteolysis (12 gene counts), and the top 10 pathways are shown in Figure 6 B. Network analysis using Cluego was carried for important filtered genes of HF and LF groups. Network analysis of filtered genes in the HF group revealed their involvement involving mitochondrial respiratory chain complex, apical plasma membrane, phospholipid translocating ATPase activity and adenylate cyclase binding (Figure 7A). And that of LF group network analysis of important filtered genes revealed their role in important processes and pathways like small ribosomal unit, $\mathrm{MHC}$ protein complex, response to hydrogen peroxide and cysteine type endopeptidase regulator activity. (Figure 7B). 


\section{Discussion}

The ability to identify bulls with greater reproductive performance would significantly improve the efficiency of the cattle industry. Identifying genomic regions, particularly individual genes associated with fertility traits and reproduction might improve the reliability of genomic estimates and are important for enhancing sire fertility via selective breeding. Bulls' fertility-related traits are moderately heritable (0.050.22) but significantly influenced by genetics (Berry and Evans 2014). Genetic studies have focused primarily on female fertility, which presents a significant challenge to improving cattle fertility because of the low heritability $(0.01-0.10)$ of these reproductive traits (Ortega et al. 2018). Therefore, improving our understanding about the genes and epigenetic modifications that contribute to bull fertility could improve reproduction success in crossbred bulls (Berry and Evans 2014; Suchocki and Szyda 2015). Genome-wide association studies (GWAS) have been effective in applying genetic markers, such as SNP markers, to determine genomic regions associated with economically important phenotypes such as fertility. Hence in the current study, we for the first time made an attempt to elucidate the various existing SNPs and novel variants of SNPs in high- and low-fertile bull spermatozoa.

In the current study, we identified a total of 77,034 variants and upon processing we could find 10594 as novel. We could identify 42290 and 34748 SNPs in HF and LF bull spermatozoa respectively. A total of 1720 and 1201 indels were observed in HF and LF groups, respectively. We detected a higher number of SNPs and Indels in the HF group bull spermatozoa than the LF group bull spermatozoa. The same trend is also observed in Genes with missense, Genes with high impact and Genes with SIFT deleterious. We also observed more number of silent mutations and less number of nonsense and missense mutations in the spermatozoa of LF bulls in comparison to HF bull spermatozoa. The genome sequencing has34 revealed that there are more variants present in the HF bull spermatozoa genome than in the LF bull spermatozoa genome reflecting the difference in the fertility of these two groups. VEP analysis of spermatozoa of LF bulls revealed some potential transcripts to be stop gained (RPS27A, NRP2, TNP2, CD74 and ZNF280B), stop lost (LYZL6, MANSC4) and deleterious (RPL13, RPS28, TNP2, JUNB, HMGB4, TTLL5, ZFN280B, LIMD1, OIT3, ORI3E12).

The genes that are stop gained plays a vital role in spermatogenesis, chromatin integrity of the spermatozoa and its blastocyst formation blastocyst development and blastocyst growth, placentation and embryogenesis fertilising ability. There was a deleterious effect on some of the ribosomal genes. Differential expression of the ribosomal proteins could affect the orchestration of ribosomes in mitochondria, which may further lead to dysfunction of spermatozoa mitochondria, which further could compromise the fertilisation process in LF group bulls. RPS27A, TNP2 play a crucial role in the process of spermatogenesis and integrity of the spermatozoa. In RPS27A gene, a mutation was observed at chromosome number 11 at position 37970665 where $\mathrm{C}>\mathrm{T}$ converted. The impact of this mutation was found to be high, and it has a stop gained effect, which will lead to premature termination of the codon and might cause the protein to be abnormally untranslated. Earlier studies indicated that dysregulated expression of RPS27A in spermatozoa had been linked to lower conception rates (Bonache et al. 2012). Ribosomal RNAs are said to be compacted at spermatogenesis (Garrido et al. 2009; Montjean et al. 2012) 
and are necessary for protein synthesis and sperm motility (Bansal et al. 2015); however, the role of mutations in these ribosomal coding regions in bull infertility has not yet been investigated. ZNF280B gene is required for the successful binding of spermatozoa to the oocyte. These genes were stop gained, indicating their protein formation is hampered, which may be the reason for compromised fertility in LF group bulls.

The important genes filtered with significant mutation in both the groups ( 92 for HF and 64 for LF) were further considered for the functional annotation and analysis studies. The KEGG pathway analysis of these genes revealed to be enriched in Ribosome, and antigen processing and presentation are the two pathways. In the ribosomal pathway, RPS17, RPS28, RPS29, RPL14, RPL13, and RPS27A genes had significant mutations. RPL14 gene has two missense mutations in BTA22 (chr22) at location 13295907 bp where $C>G$ and other mutations at position 13295942 bp where $C>T$. Ribosomal protein L14 (RPL14) was found to be prevalent in the testes and is reported to be associated with low fertility in crossbred bulls $[16,45,46]$. Similarly, RPS28 gene has variation at Chr 7 at position $16968899 \mathrm{bp}$ and T>C, a missense variation with a deleterious effect (SIFT value of 0). RPS17 also has a missense variation at Chr 21 at position $22841433 \mathrm{bp}$. RPL13 is seen to have missense variation, and the mutation also has a deleterious effect (SIFT value of 0 ). The RPL13 gene has variation at BTA18 at 14490777 bp where A>G. SNP determined with deleterious effect were reported to change the function of a protein and hence contribute to a genetic disorder (Care et al. 2007). GO analysis of the RPL13 gene revealed its role in mRNAs' stabilisation and translational regulation during spermatogenesis (Öztürk et al. 2016). The deleterious effect of SNP in this gene may cause dysregulation to the spermatogenesis process. In the RPS29 gene, in chromosome number 10, we found a missense mutation from $\mathrm{G}>\mathrm{C}$ at $26779309 \mathrm{bp}$. Genetic variation in RPS29, RPS27A, and RPL13 were reported to be resulted in a low pregnancy rate in humans (Bonache et al. 2012). GO analysis of RPS 29 revealed its molecular function in binding to the $\mathrm{Zn}$ ion. Zinc is required for the survival of germ cells and the development of spermatogenesis. It also protects the sperm flagellum from early oxidation, as it will attach to sulfhydryl groups of outer dense fibre protein cysteine groups and hence plays a pivotal role in the reduction of oxidation of sperm membranes (Kerns et al. 2018). All these proteins have a significant role in producing healthy and active spermatozoa. Mutations to these important genes might have contributed to the defects in the process of spermatogenesis in LF group bulls.

Another pathway in which the majority of the mutated genes were involved was antigen processing and presentation pathway, which is not well described earlier. CD74, PSME1, BOLA-DRA are the three mutated genes in this pathway. CD74 was reported to play a critical role as cytokines contribute to testicular function and maintain male reproductive health (Loveland et al. 2017). This gene was found to have a mutation which is stop gained at position $61755486 \mathrm{bp}$ in chromosome 7 , where $\mathrm{C}>\mathrm{A}$ transition and two missense mutations at Chr 7 (at positions 61750597bp where C>T; at 61752414bp where T>A). GO analysis revealed this gene has beta-amyloid binding and cytokine receptor activity as its molecular function and, positive regulation of cytokine-mediated signalling pathway as a biological process. CD74 was previously reported to have a vital role in controlling the antigen presentation for immune responses in chickens (Singh et al. 2016) and cyprinid fish (Hu et al. 2017), and it is highly upregulated in low fertile 
(Prakash et al., 2021). Proteasome activator subunit 1(PSME1) was found to have a mutation at chromosome number 10 (bta10) at position 21012919bp where there is a transition of $A>C$. This gene was involved in various important biological processes like positive regulation of endopeptidase activity, antigen processing and presentation of exogenous antigen, and regulation of catabolic proteasome protein. PSME1 is also involved in epididymis secretory sperm binding protein and are essential for promoting sperm motility (Bosler et al. 2014; Ozbek et al. 2021). BOLA-DRA, a Major histocompatibility complex, class II, DR alpha(BOLA-DRA) gene was observed to have two missense mutations in Chr 23 at $25840067 \mathrm{bp}, 25840771 \mathrm{bp}$ and both transitions were found to be $\mathrm{G}>\mathrm{A}$. This gene was also reported to have a role in membrane integrity and sperm morphology (Kasimanickam et al. 2019). Another important gene observed to have missense mutation is the tumour protein, translationally-controlled 1(TPT1) gene. TPT gene has a major role in apoptosis, cellular differentiation, and sperm functions [55]. This gene has missense variation at chr 12 (bta12) at position $15475714 \mathrm{bp}$ where $\mathrm{A}$ is replaced with $\mathrm{T}$. It is reportedly abundant in the sperm of humans (Zhao et al. 2006) and chickens (Singh et al. 2016) but downregulated in oligozoospermic men (Montjean et al. 2012).

Network analysis of different GO terms and KEGG pathway interaction analysis revealed that there is mutation in the intronic regions of the genes related to the NADH dehydrogenase activity (ND3, ND5), Oxidoreductase activity (ND3, ND5), adenylate cyclase binding (ADRB2, AKAP12) and phospholipid translocating activity (ATP8B1, ATP9A) in the spermatozoa of HF bulls, which is not having a deleterious effect and this mutation is moderate and silence accepted. In the LF bull spermatozoa mutation in important genes were involved in the ribosomal pathway (RPL8, RPS14, RPL18, RPS27A, RPS11, RPS10, RPL19, RPS12, RPS9, RPS7, RPL21, RPS8, RPL23, RPS5, RPS26, RPS25, RPS28, RPS27, RPL27A, RPL37A), regulation of actin cytoskeleton (APC2, AKAP4, PXN, ARPC4, ACTB, ACTG1, FGF16, PFN1), spliceosome (HSPA8, PRPF38B, DDX5, TRA2A) and ubiquitin mediated proteolysis (UBE2Q2, UBE2E3, TRIM37, TRIM32, BIRC3).

Profilin 1 (PFN1) modulates actin and is involved in oocyte maturation, fertilisation, embryo development (Rawe et al. 2006) and spermatogenesis (Selvaraju et al. 2018). Ribosomes are actively involved in protein translation in spermatozoa (Gur and Breitbart 2006). Ribosomal protein S8 (RPS8) is found abundant in spermatozoa of humans (Zhao et al. 2006), whereas Ribosomal protein L14 (RPL 14) is abundant in the testis of Bos taurus and Bos indicus bulls (Selvaraju et al. 2018; Raval et al. 2019). ACTB is expressed in spermatozoa and is distributed in the acrosomal and post-acrosomal regions of ejaculated spermatozoa where it is involved in membrane changes during acrosome reaction with an important implication on sperm function (Casale et al. 1988). AKAP4 is one of the major components of the sperm fibrous sheath, a structure known to be involved in sperm motility. The molecular chaperone HSPA8 plays a key role in remodelling the sperm surface during capacitation. It is established that mice lacking HSPA gene are infertile and spermatozoa that fail to interact with the zona pellucida of the oocyte consistently lack HSPA2 protein expression. HSPA8 was also reported to have a role in protecting spermatozoa in the oviduct (Elliott et al. 2009). AKAPs can bind other protein kinases, protein phosphatases, ion channels, and small GTP binding proteins and thus serve as platforms for the integration of cAMP and other signalling pathways (Michel and Scott 2002; Skroblin et al. 2010). AKAP 
proteins are reported to be key molecules in the biochemical machinery regulating the functions of flagella and cilia. Spermatozoa from mice lacking AKAP4 failed to show progressive motility and the male mice were infertile (Miki et al. 2002).

These genes play a vital role in spermatogenesis, microtubule formation in the spermatozoa, and the process of ubiquitination. These genes were found to have high impact mutation, which hampers the important processes which might be the probable cause for the low fertility in LF bulls.

\section{Conclusion}

In conclusion, the findings of the present study showed that RNA-seq is a potential approach for genomic profiling variants and mutational events in relation to fertility. Using RNA-seqtechnique, candidate genes for high and low fertility characteristics of interest in bulls were determined and discovered the functional assessment of genes with substantial mutations related to bull fertility. Specifically, SNPs in candidate genes including TPT1, BOLA-DRA, CD74, RPS17, RPS28, RPS29, RPL14, RPL13 and RPS27A, which are linked to sperm functionality, survival, and protection from oxidative stress and fertilising potential, were related to bull fertility. The variation in these genes with the highly significant genic region might be associated with low fertility in breeding bulls.

\section{Declarations}

\section{Author contributions}

MKS, ESK, TRT, - Methodology, Experiment, Writing original draft, Data curation. AK, AVConceptualization, Project administration, Supervision, writing review and editing. MKS, MAP, PN, KR and NP - Data curation and bio-informatic analysis. MKS, PN and EK - Methodology, data curation. AV Formal analysis, writing review and editing

\section{Conflict of interest}

The authors of the present manuscript hereby declare that they do not possess any conflict among themselves

\section{Acknowledgements}

The authors thank the Director, ICAR-National Dairy Research Institute, India for providing necessary facilities for carrying out this research. The authors acknowledge the help from Sandor ${ }^{\circledR}$ Lifesciences Pvt. Ltd. Banjara Hills, Hyderabad, India for sequencing of samples.

\section{Data availability}

The datasets presented in this study can be made available upon request to the author. 


\section{Consent of participation}

All authors consent to participate in this publication.

\section{Consent for publication}

All authors consent to publish the manuscript.

\section{References}

1. Andrew S (2010) FastQC: A quality control tool for high throughput sequence data. Available online at: http://www.bioinformatics.babraham.ac.uk/projects/fastqc

2. Arcuri F, Papa S, Carducci A, Romagnoli R, Liberatori S, Riparbelli MG, Sanchez JC, Tosi P, del Vecchio MT (2004) Translationally controlled tumor protein (TCTP) in the human prostate and prostate cancer cells: expression, distribution, and calcium binding activity. Prostate. https://doi.org/10.1002/pros.20054

3. Aslam MM, Sharma VK, Pandey S, Kumaresan A, Srinivasan A, Datta TK, Mohanty TK, Yadav S (2018) Identification of biomarker candidates for fertility in spermatozoa of crossbred bulls through comparative proteomics. Theriogenology. https://doi.org/10.1016/j.theriogenology.2018.06.021

4. Bansal SK, Gupta N, Sankhwar SN, Rajender S (2015) Differential genes expression between fertile and infertile spermatozoa revealed by transcriptome analysis. PloS One. https://doi.org/10.1371/journal.pone.0127007

5. Berry DP, Evans R (2014) Genetics of reproductive performance in seasonal calving beef cows and its association with performance traits. J Anim Sci. https://doi.org/10.2527/jas.2013-6723

6. Bonache S, Mata A, Ramos MD, Bassas L, Larriba S (2012) Sperm gene expression profile is related to pregnancy rate after insemination and is predictive of low fecundity in normozoospermic men. Hum Reprod. https://doi.org/10.1093/humrep/des074

7. Bosler J, Davies K, Neal-Perry G (2014) Opiorphin, an endogenous neutral endopeptidase inhibitor, increases sperm motility in men diagnosed with infertility. Fertil Steril. https://doi.org/10.1016/j.fertnstert.2014.07.1170

8. Braundmeier A, Miller D (2001) Invited review: the search is on: finding accurate molecular markers of male fertility. J Dairy Sci. https://doi.org/10.3168/jds.S0022-0302(01)74633-4Get

9. Butler ML, Bormann JM, Weaber RL, Grieger DM, Rolf MM (2020) Selection for bull fertility: a review. Transl Anim Sci. https://doi.org/10.1093/tas/txz174

10. Care MA, Needham CJ, Bulpitt AJ, Westhead DR (2007) Deleterious SNP prediction: be mindful of your training data! Bioinformatics. https://doi.org/10.1093/bioinformatics/bt1649

11. Casale A, Camatini M, Skalli O, Gabbiani G (1988) Characterization of actin isoforms in ejaculated boar spermatozoa. Gamete Res. https://doi.org/10.1002/mrd.1120200204 
12. Cingolani P, Platts A, Wang LL, Coon M, Nguyen T, Wang L, Land SJ, Lu X, Ruden DM (2012) A program for annotating and predicting the effects of single nucleotide polymorphisms, SnpEff: SNPs in the genome of Drosophila melanogaster strain w1118; iso-2; iso-3. Fly. https://doi.org/10.4161/fly.19695

13. Cole JB, Wiggans GR, Ma L, Sonstegard TS, Lawlor TJ, Crooker BA, Van Tassell CP, Yang J, Wang S, Matukumalli LK, Da Y (2011) Genome-wide association analysis of thirty one production, health, reproduction and body conformation traits in contemporary US Holstein cows. BMC Genom. https://doi.org/10.1186/1471-2164-12-408

14. Craig DW, Stephan DA (2005) Applications of whole-genome high-density SNP genotyping. Expert Rev Mol Diagn. https://doi.org/10.1586/14737159.5.2.159

15. Danecek P, Auton A, Abecasis G, Albers CA, Banks E, DePristo MA, Handsaker RE, Lunter G, Marth GT, Sherry ST, McVean G (2011) The variant call format and VCFtools. Bioinformatics. https://doi.org/10.1093/bioinformatics/btr330

16. DasGupta M, Kumaresan A, Saraf KK, Paul N, Sajeevkumar T, Karthikkeyan G, Prasad TK, Modi PK, Ramesha K, Manimaran A, Jeyakumar S (2021) Deciphering metabolomic alterations in seminal plasma of crossbred (Bos taurus X Bos indicus) bulls through comparative deep metabolomic analysis. Andrologia. https://doi.org/10.1111/and.14253

17. DeJarnette J, Marshall C, Lenz R, Monke D, Ayars W, Sattler C (2004) Sustaining the fertility of artificially inseminated dairy cattle: the role of the artificial insemination industry. J Dairy Sci. https://doi.org/10.3168/jds.S0022-0302(04)70065-X

18. Elliott RM, Lloyd RE, Fazeli A, Sostaric E, Georgiou AS, Satake N, Watson PF, Holt WV (2009) Effects of HSPA8, an evolutionarily conserved oviductal protein, on boar and bull spermatozoa. Reproduction. https://doi.org/10.1530/REP-08-0298

19. Feugang J, Rodriguez-Osorio N, Kaya A, Wang H, Page G, Ostermeier GC, Topper EK, Memili E (2010) Transcriptome analysis of bull spermatozoa: implications for male fertility. Reprod Biomed Online. https://doi.org/10.1016/j.rbmo.2010.06.022

20. Garrido C, Carbú M, Fernández-Acero F, Boonham N, Colyer A, Cantoral JM, Budge G (2009) Development of protocols for detection of Colletotrichum acutatum and monitoring of strawberry anthracnose using real-time PCR. Plant Pathol. https://doi.org/10.1111/j.1365-3059.2008.01933.x

21. Gur Y, Breitbart H (2006) Mammalian sperm translate nuclear-encoded proteins by mitochondrialtype ribosomes. Genes Dev. http://www.genesdev.org/cgi/doi/10.1101/gad.367606.

22. Haegeman A, Williams J, Law A, Van Zeveren A, Peelman L (2003) Mapping and SNP analysis of bovine candidate genes for meat and carcass quality. Anim Genet. https://doi.org/10.1046/j.13652052.2003.01008.x

23. Hayes BJ, Bowman PJ, Chamberlain AJ, Goddard ME (2009) Invited review: Genomic selection in dairy cattle: Progress and challenges. J Dairy Sci. https://doi.org/10.3168/jds.2008-1646

24. Heaton MP, Harhay GP, Bennett GL, Stone RT, Grosse WM, Casas E, Keele JW, Smith TP, ChitkoMcKown CG, Laegreid WW (2002) Selection and use of SNP markers for animal identification and 
paternity analysis in US beef cattle. Mamm Genome. https://doi.org/10.1007/s00335-001-2146-3

25. Hu F, Xu K, Zhou Y, Wu C, Wang S, Xiao J, Wen M, Zhao R, Luo K, Tao M, Duan W (2017) Different expression patterns of sperm motility-related genes in testis of diploid and tetraploid cyprinid fish. Biol Reprod. https://doi.org/10.1093/biolre/iox010

26. Immler S (2018) The sperm factor: paternal impact beyond genes. Heredity. https://doi.org/10.1038/s41437-018-0111-0

27. Kasimanickam R, Kasimanickam V, Arangasamy A, Kastelic J (2019) Sperm and seminal plasma proteomics of high-versus low-fertility Holstein bulls. Theriogenology. https://doi.org/10.1016/j.theriogenology.2018.11.032

28. Kerns K, Zigo M, Drobnis EZ, Sutovsky M, Sutovsky P (2018) Zinc ion flux during mammalian sperm capacitation. Nat Commun. https://doi.org/10.1038/s41467-018-04523-y

29. Kropp J, Salih SM, Khatib H (2014) Expression of microRNAs in bovine and human pre-implantation embryo culture media. Front Genet. https://doi.org/10.3389/fgene.2014.00091

30. Kumaresan A, Elango K, Datta TK, Morrell JM (2021) Cellular and molecular insights into the etiology of subfertility/infertility in crossbred bulls (Bos Taurus $\times$ Bos indicus): A review. Front Cell Dev Biol. https://doi.org/10.3389/fcell.2021.696637

31. Li H, Handsaker B, Wysoker A, Fennell T, Ruan J, Homer N, Marth G, Abecasis G, Durbin R (2009) The sequence alignment/map format and SAMtools. Bioinformatics.

https://doi.org/10.1093/bioinformatics/btp352

32. Locatelli Y, Forde N, Blum H, Graf A, Piégu B, Mermillod P, Wolf E, Lonergan P, Saint-Dizier M (2019) Relative effects of location relative to the corpus luteum and lactation on the transcriptome of the bovine oviduct epithelium. BMC Genom. https://doi.org/10.1186/s12864-019-5616-2

33. Loveland KL, Klein B, Pueschl D, Indumathy S, Bergmann M, Loveland BE, Hedger MP, Schuppe HC (2017) Cytokines in male fertility and reproductive pathologies: immunoregulation and beyond. Front Endocrinol. https://doi.org/10.3389/fendo.2017.00307

34. Lucy M (2001) Reproductive loss in high-producing dairy cattle: where will it end? J Dairy Sci.https://doi.org/10.3168/jds.S0022-0302(01)70158-0

35. Mai M, Sahana G, Christiansen F, Guldbrandtsen B (2010) A genome-wide association study for milk production traits in Danish Jersey cattle using a $50 \mathrm{~K}$ single nucleotide polymorphism chip. J Anim Sci. https://doi.org/10.2527/jas.2009-2713

36. Meredith B, Lynn D, Berry D, Kearney F, Bradley D, Finlay E, Fahey A (2013) A genome-wide association study for somatic cell score using the Illumina high-density bovine beadchip identifies several novel QTL potentially related to mastitis susceptibility. Front Genet. https://doi.org/10.3389/fgene.2013.00229

37. Michel JJC, Scott JD (2002) AKAP mediated signal transduction. Annu Rev Pharmacol. Toxicol. https://doi.org/10.1146/annurev.pharmtox.42.083101.135801

38. Miki K, Willis WD, Brown PR, Goulding EH, Fulcher KD, Eddy EM (2002) Targeted disruption of the Akap4 gene causes defects in sperm flagellum and motility. Dev Biol. 
https://doi.org/10.1006/dbio.2002.0728

39. Montjean D, De La Grange P, Gentien D, Rapinat A, Belloc S, Cohen-Bacrie P, Menezo Y, Benkhalifa M (2012) et al. Sperm transcriptome profiling in oligozoospermia. J Assist Reprod Genet. https://doi.org/10.1007/s10815-011-9644-3

40. Nayeri S, Stothard P (2016) Tissues, metabolic pathways and genes of key importance in lactating dairy cattle. Springer Sci Rev. https://doi.org/10.1007/s40362-016-0040-3

41. Newton-Cheh C, Hirschhorn JN (2005) Genetic association studies of complex traits: design and analysis issues. Mutat Res - Fundam Mol Mech Mutagen. https://doi.org/10.1016/j.mrfmmm.2005.01.006

42. Ortega MS, Moraes JG, Patterson DJ, Smith MF, Behura SK, Poock S, Spencer TE (2018) Influences of sire conception rate on pregnancy establishment in dairy cattle. Biol Reprod. https://doi.org/10.1093/biolre/ioy141

43. Ostermeier GC, Dix DJ, Miller D, Khatri P, Krawetz SA (2002) Spermatozoal RNA profiles of normal fertile men. Lancet. https://doi.org/10.1016/S0140-6736(02)09899-9

44. Ozbek IY, Mumusoglu S, Polat M, Bozdag G, Sokmensuer LK, Yarali H (2021) Comparison of single euploid blastocyst transfer cycle outcome derived from embryos with normal or abnormal cleavage patterns. Reprod Biomed Online. https://doi.org/10.1016/j.rbmo.2021.02.005

45. Öztürk E, Arlov $\emptyset$, Aksel S, Li L, Ornitz DM, Skjåk-Bræk G, Zenobi-Wong M (2016) Sulfated hydrogel matrices direct mitogenicity and maintenance of chondrocyte phenotype through activation of FGF signaling. Adv Funct Mater. ttps://doi.org/10.1002/adfm.201600092

46. Paul N, Kumaresan A, Das Gupta M, Nag P, Guvvala PR, Kuntareddi C, Sharma A, Selvaraju S, Datta TK (2021) Transcriptomic profiling of buffalo spermatozoa reveals dysregulation of functionally relevant mRNAs in low-fertile bulls. Front Vet Sci. https://doi.org/10.3389/fvets.2020.609518

47. Peddinti D, Nanduri B, Kaya A, Feugang JM, Burgess SC, Memili E (2008) Comprehensive proteomic analysis of bovine spermatozoa of varying fertility rates and identification of biomarkers associated with fertility. BMC Syst Biol. https://doi.org/10.1186/1752-0509-2-19

48. Prakash MA, Kumaresan A, King JPES, Nag P, Sharma A, Sinha MK, Kamaraj E, Datta TK (2021) Comparative transcriptomic analysis of spermatozoa from high-and low-fertile crossbred bulls: Implications for fertility prediction. Front Cell Dev Biol. 10.3389/fcell.2021.647717

49. Pryce J, Royal M, Garnsworthy P, Mao I (2004) Fertility in the high-producing dairy cow. Livest Prod Sci. https://doi.org/10.1016/S0301-6226(03)00145-3

50. Raval NP, Shah TM, George L-B, Joshi CG (2019) Insight into bovine (Bos indicus) spermatozoal whole transcriptome profile. Theriogenology. https://doi.org/10.1016/j.theriogenology.2019.01.037

51. Rawe VY, Payne C, Schatten G (2006) Profilin and actin-related proteins regulate microfilament dynamics during early mammalian embryogenesis. Hum Reprod.

https://doi.org/10.1093/humrep/dei480

52. Selvaraju S, Parthipan S, Somashekar L, Binsila BK, Kolte AP, Arangasamy A, Ravindra JP, Krawetz SA (2018) Current status of sperm functional genomics and its diagnostic potential of fertility in 
bovine (Bos taurus). Syst Biol Reprod Med. https://doi.org/10.1080/19396368.2018.1444816

53. Singh R, Shafeeque C, Sharma S, Singh R, Mohan J, Sastry KV, Saxena VK, Azeez PA (2016) Chicken sperm transcriptome profiling by microarray analysis. Genome. https://doi.org/10.1139/gen-20150106

54. Skroblin P, Grossmann S, Schäfer G, Rosenthal W, Klussmann E (2010) Mechanisms of protein kinase A anchoring. Int Rev Cell Mol Biol. https://doi.org/10.1016/S1937-6448(10)83005-9

55. Suchocki T, Szyda J (2015) Genome-wide association study for semen production traits in HolsteinFriesian bulls. J Dairy Sci. https://doi.org/10.3168/jds.2014-8951

56. Suh T, Schenk J, Seidel Jr G (2005) High pressure flow cytometric sorting damages sperm.

Theriogenology. https://doi.org/10.1016/j.theriogenology.2005.02.002

57. Taylor JF, Schnabel RD, Sutovsky P (2018) Genomics of bull fertility. Animal. https://doi.org/10.1017/S1751731118000599

58. Tishkoff SA, Reed FA, Ranciaro A, Voight BF, Babbitt CC, Silverman JS, Powell K, Mortensen HM, Hirbo JB, Osman M, Ibrahim M (2007) Convergent adaptation of human lactase persistence in Africa and Europe. Nat Genet. https://doi.org/10.1038/ng1946

59. Vallet J, Freking B, Leymaster K, Christenson R (2005) Allelic variation in the erythropoietin receptor gene is associated with uterine capacity and litter size in swine. Anim Genet. https://doi.org/10.1111/j.1365-2052.2005.01233.x

60. Vychodilova-Krenkova L, Matiasovic J, Horin P (2005) Single nucleotide polymorphisms in four functionally related immune response genes in the horse: CD14, TLR4, C, andFc R1 alpha. Int J Immunogenet. https://doi.org/10.1111/j.1744-313X.2005.00522.x

61. Werner F, Durstewitz G, Habermann FA, Thaller G, Krämer W, Kollers S, Buitkamp J, Georges M, Brem G, Monser J, Fries R (2004) Detection and characterisation of SNPs useful for identity control and parentage testing in major European dairy breeds. Anim Genet. https://doi.org/10.1046/j.13652052.2003.01071.x

62. Zhao Y, Li Q, Yao C, Wang Z, Zhou Y, Wang Y, Liu L, Wang Y, Wang L, Qiao Z (2006) Characterisation and quantification of mRNA transcripts in ejaculated spermatozoa of fertile men by serial analysis of gene expression. Hum Reprod. https://doi.org/10.1093/humrep/del027

63. Zimin AV, Delcher AL, Florea L, Kelley DR, Schatz MC, Puiu D, Hanrahan F, Pertea G, Van Tassell CP, Sonstegard TS, Marcais G (2009) A whole-genome assembly of the domestic cow, Bos taurus. Genome Biol. https://doi.org/10.1186/gb-2009-10-4-r42

\section{Tables}

\section{Table 1: Summary Statistics of total SNPs Identified}




\begin{tabular}{|lll|}
\hline Category & HF & LF \\
\hline Variant Processed & 42290 & 34748 \\
\hline Existing Variants & 36175 & 30075 \\
\hline Novel Variants & 6115 & 4673 \\
\hline
\end{tabular}

Table 2: Summary Statistics for Important filtered Genes with their functional class

\begin{tabular}{|lll|}
\hline Category & HF & LF \\
\hline Total Gene with variants & 5640 & 4878 \\
\hline Gene With Novel Variant & 1453 & 1109 \\
\hline Genes with missense & 101 & 70 \\
\hline Genes with high impact & 4 & 10 \\
\hline Genes with SIFT deleterious & 21 & 13 \\
\hline
\end{tabular}

Table 3. List of total type of mutations observed in crossbred bull spermatozoa.

\begin{tabular}{|llll|}
\hline Number of effects by functional class & Total In Crossbred bull spermatozoa & HF & LF \\
\hline MISSENSE & 499 & 301 & 198 \\
\hline NONSENSE & 20 & 12 & 8 \\
\hline SILENT & 1114 & 365 & 749 \\
\hline Missense / Silent ratio & 0.44 & 0.82 & 0.26 \\
\hline Ts/Tv (transitions / transversions) & 1.89 & 1.87 & 1.925 \\
\hline
\end{tabular}

Table 4. Nucleotide changes in identified SNPs of crossbred bull spermatozoa

\begin{tabular}{|lllll|}
\hline Nucleotide & A & C & G & T \\
\hline A & 0 & 4730 & 11098 & 3408 \\
\hline C & 3029 & 0 & 2620 & 12448 \\
\hline G & 12536 & 2665 & 0 & 3087 \\
\hline T & 3390 & 11355 & 2822 & 0 \\
\hline
\end{tabular}

\section{Figures}


A

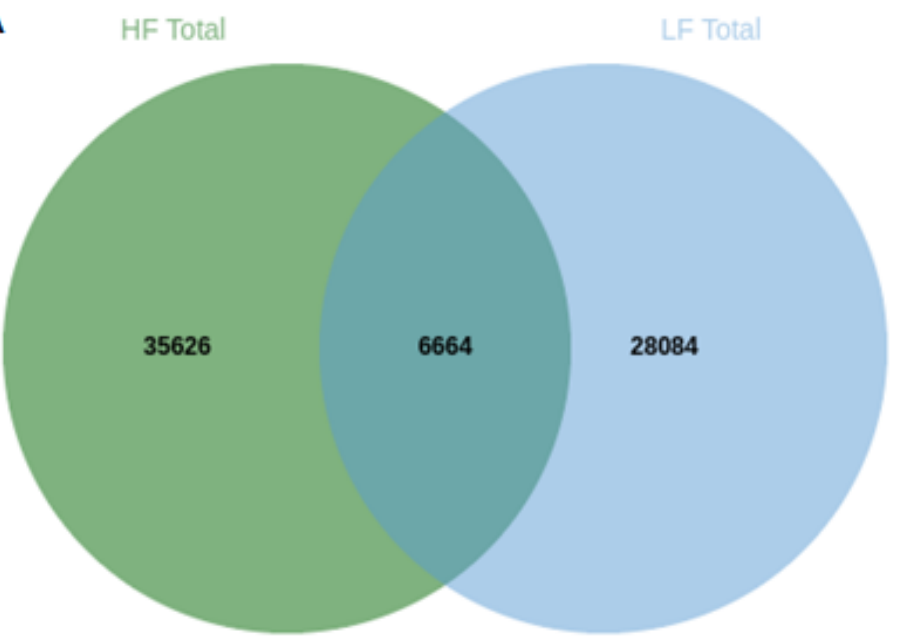

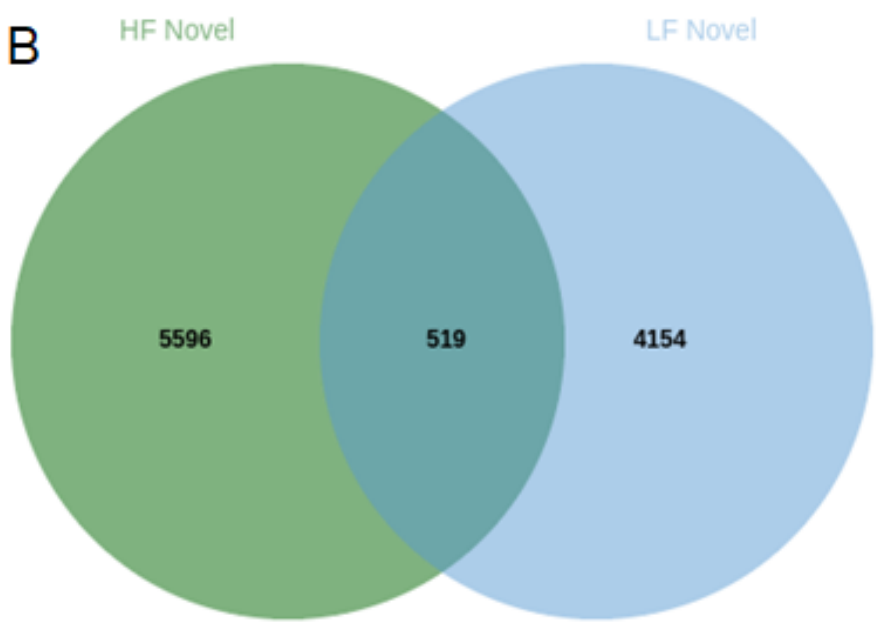

\section{Figure 1}

A. Total and B. novel variants observed in HF and LF crossbreed bull spermatozoa
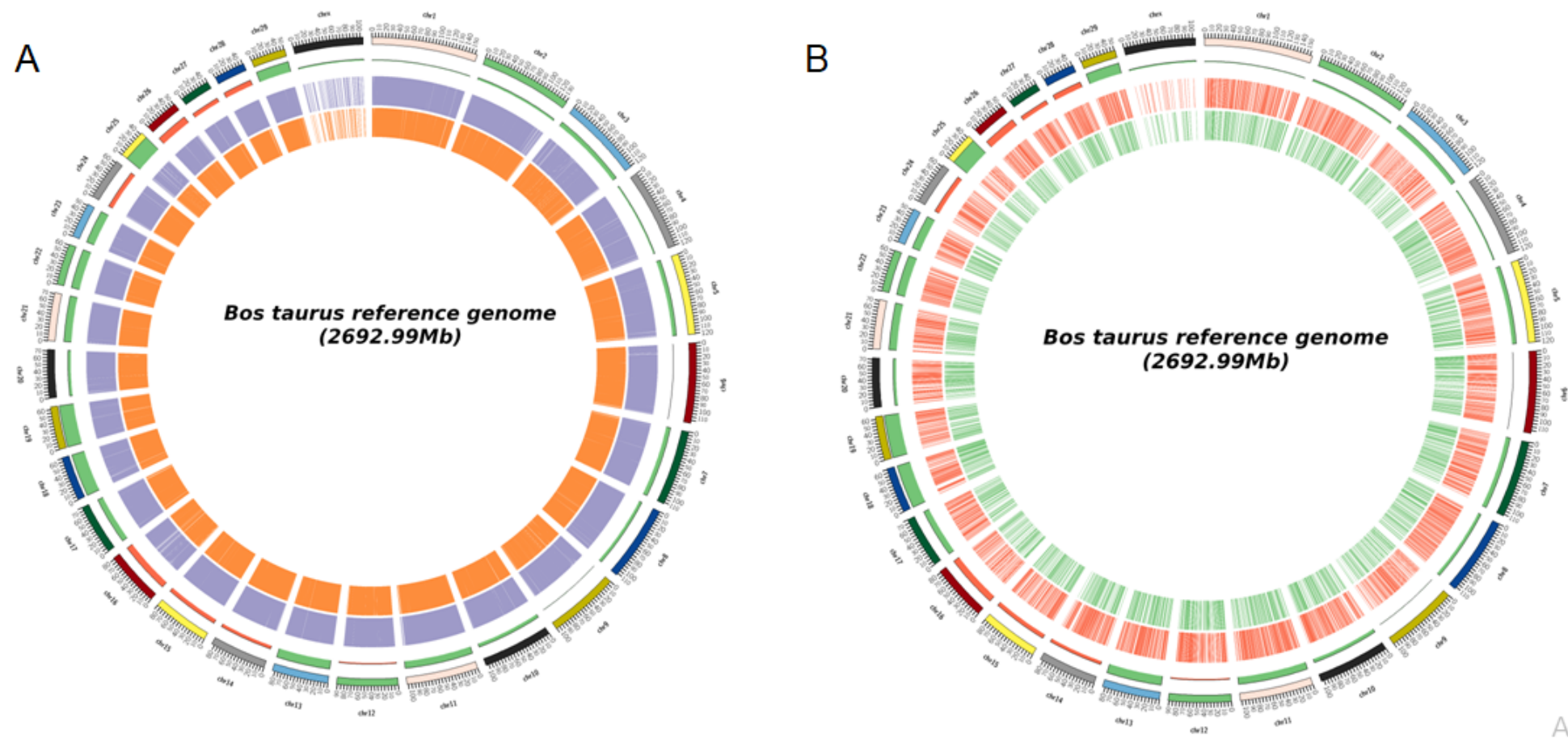

Figure 2

Circos plot of the global distribution of genes, SNP variants, and signature of selective sweeps along 29 autosomes and $\mathrm{X}$ chromosomes. The chromosomes were represented in the outermost, next $\mathrm{GC} \%$ for the chromosome. A. 2 circle highlights all the variants observed outer being HF (purple) and next is LF (orange). B. 2 circle highlights novel variants observed outer being HF (red) and next is LF (green). 
A

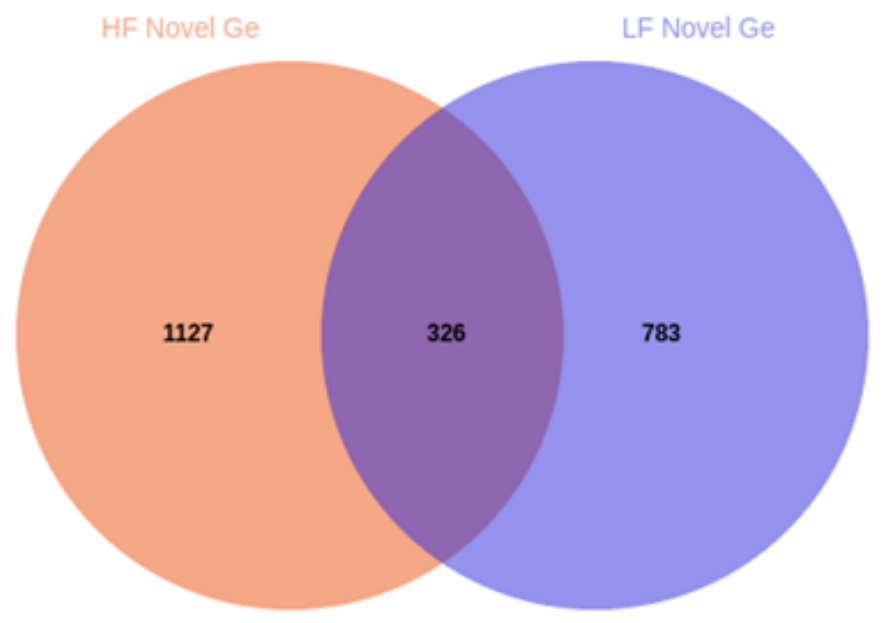

B

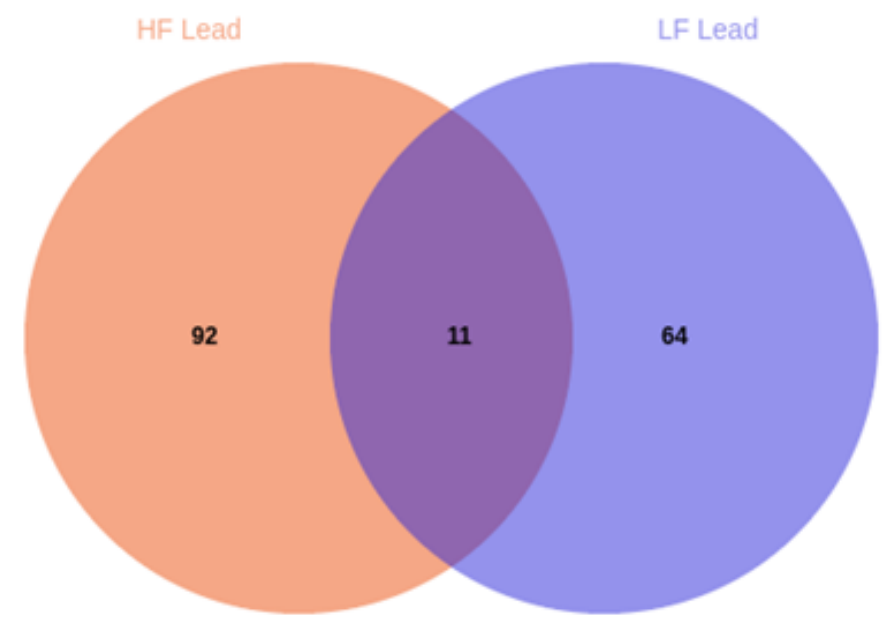

\section{Figure 3}

Venn diagram of HF and LF. A) Genes with the novel variants B) Important filtered gene with consequence as missense variant, Impact is high, and SIFT is deleterious

A

Coding Consequences

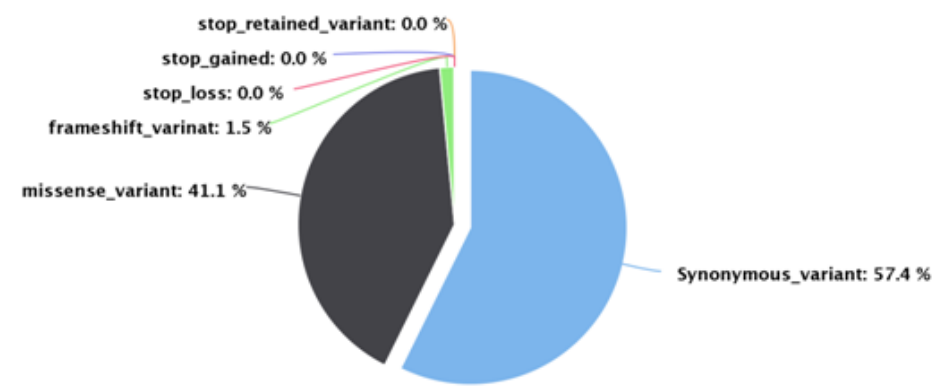

B

Coding Consequences

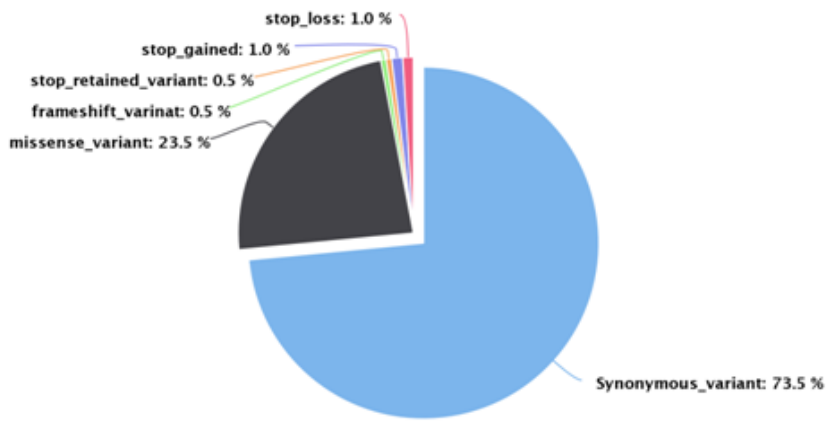

\section{Figure 4}

Summary Statistics for Coding Consequences. A) HF sample B) LF sample 


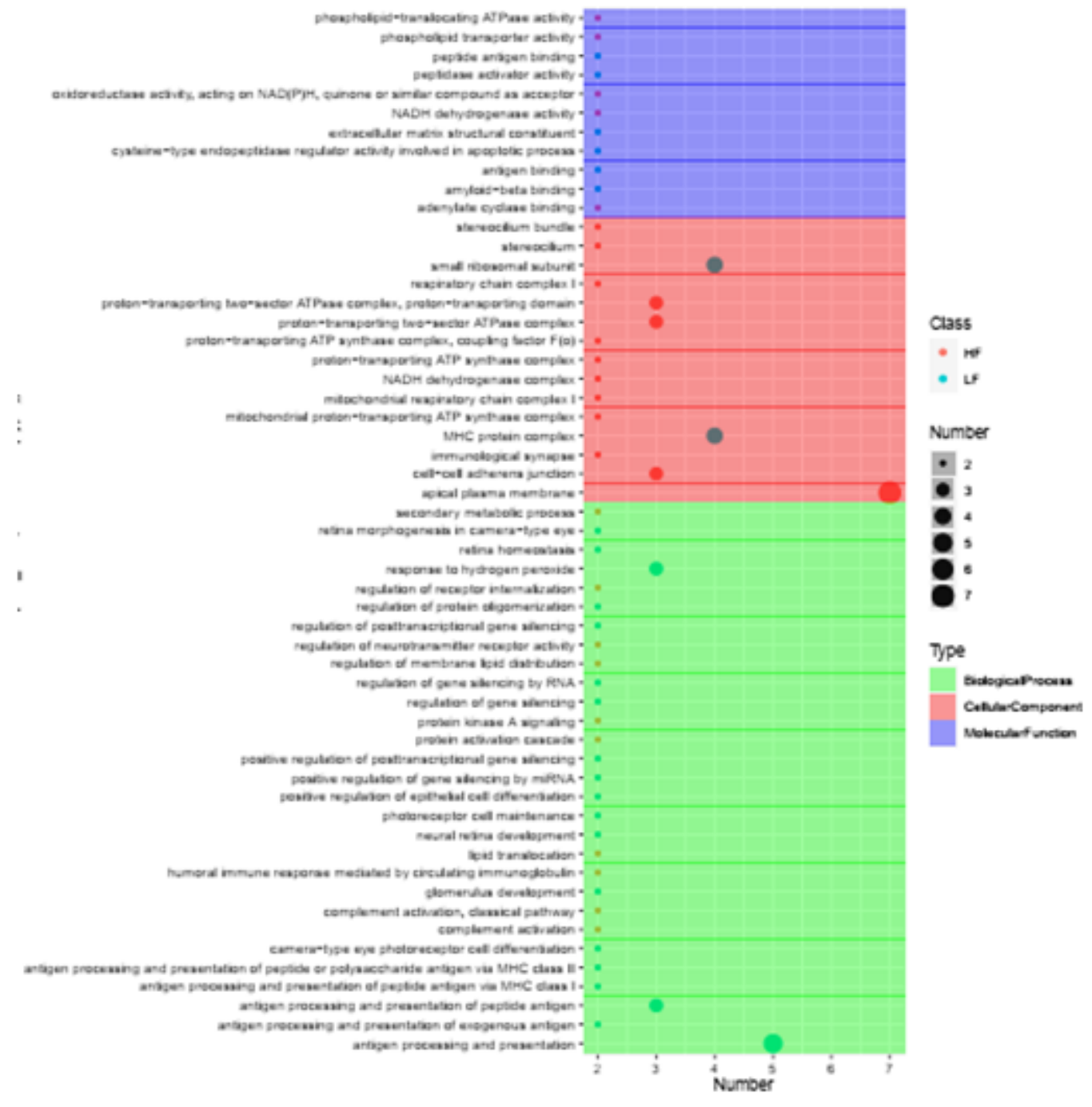

Figure 5

Functional annotation of various Gene ontology terms (Biological Processes, molecular functions and cellular components) of novel variants observed in high- and low- fertile groups of bulls 

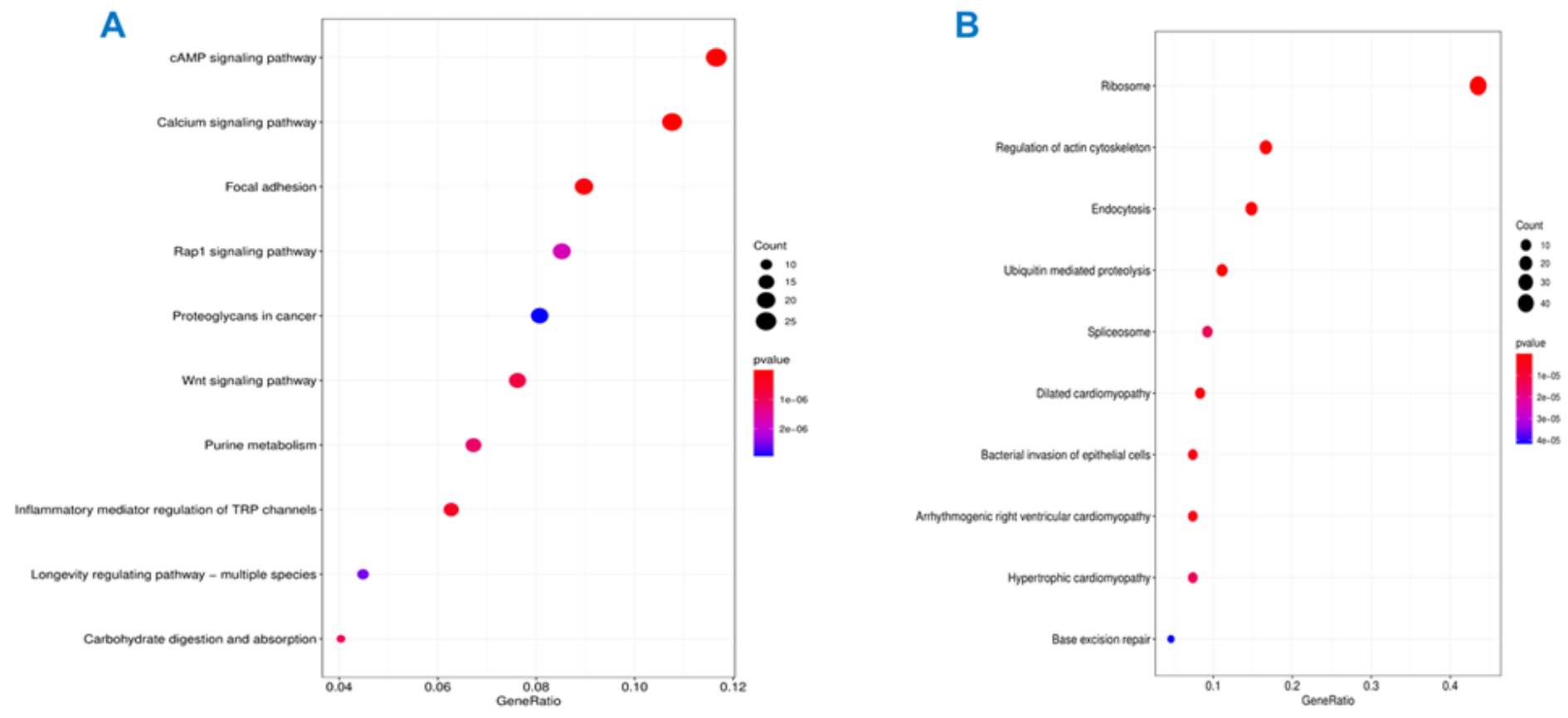

Figure 6

KEGG pathway enrichment analysis of novel variants. A. High- Fertile bull group. B. Low-Fertile groups.

A

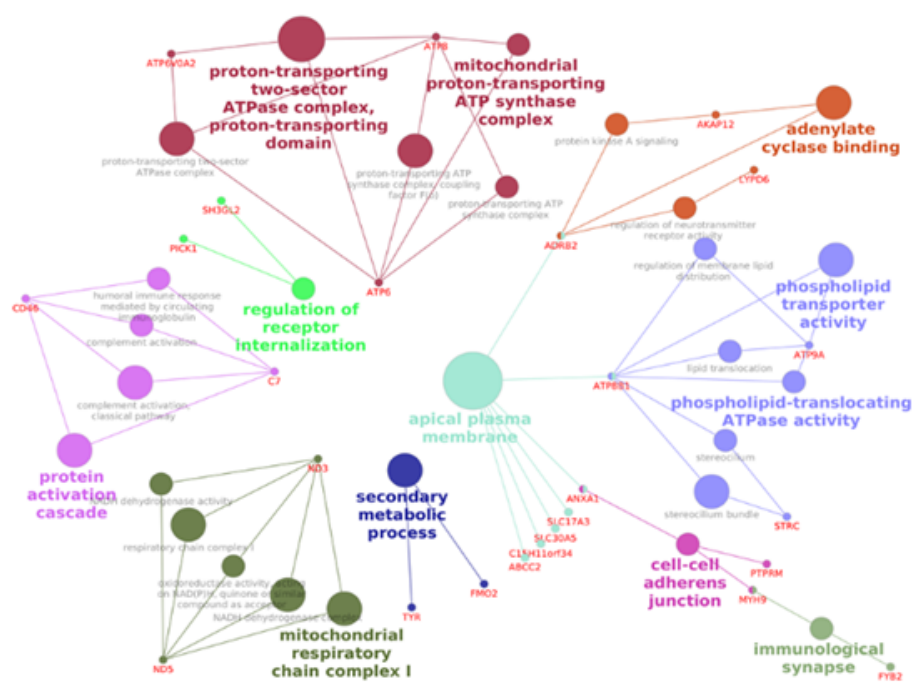

$\mathrm{B}$

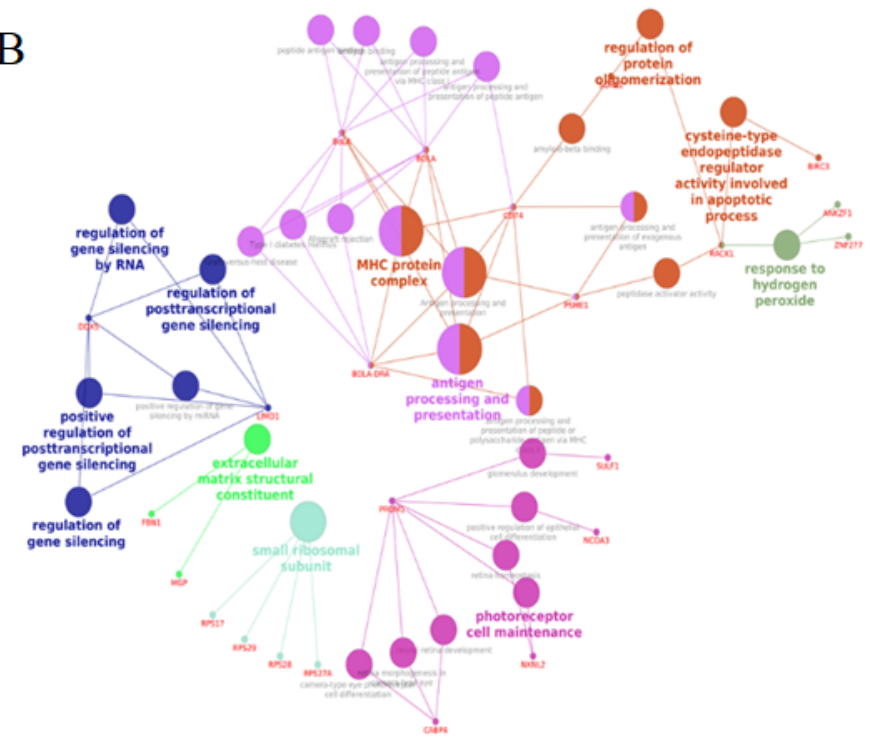

Figure 7

Interaction network analysis of various biological processes, molecular functions and pathways expressed by the novel variants

A. High- Fertile bull group. B. Low-Fertile groups

Supplementary Files 
This is a list of supplementary files associated with this preprint. Click to download.

- SupplementaryFile.xlsx

- SupplementaryFigures.docx

- SUPPLEMENTARYTables.docx 